\title{
Medical Management of Hyperglycemia in Type 2 Diabetes: A Consensus Algorithm for the Initiation and Adjustment of Therapy
}

\section{A consensus statement of the American Diabetes Association and the European Association for the Study of Diabetes}

DAVID M. NATHAN, MD ${ }^{1}$

JOHN B. BUSE, MD, PHD ${ }^{2}$

MAYER B. DAVIDSON, MD ${ }^{3}$

Ele Ferrannini, MD ${ }^{4}$

The consensus algorithm for the medical management of type 2 diabetes was published in August 2006 with the expectation that it would be updated, based on the availability of new interventions and new evidence to establish their clinical role. The authors continue to endorse the principles used to develop the algorithm and its major features. We are sensitive to the risks of changing the algorithm cavalierly or too frequently, without compelling new information. An update to the consensus algorithm published in January 2008 specifically addressed safety issues surrounding the thiazolidinediones. In this revision, we focus on the new classes of medications that now have more clinical data and experience.

$\mathrm{T}$ he epidemic of type 2 diabetes and the recognition that achieving specific glycemic goals can substantially reduce morbidity have made the effective treatment of hyperglycemia a top priority (1-3). While the management of hyperglycemia, the hallmark metabolic abnormality associated with type 2 diabetes, has historically taken center stage in the treatment of diabetes, therapies directed at other coincident features, such as dyslipidemia, hypertension, hypercoagulability, obesity, and insulin resistance, have also been a major focus of research and therapy. Maintaining glycemic levels as close to the nondiabetic range as possible has been demonstrated to have a powerful
Diabetes Care 32:193-203,

\author{
RURY R. HOLMAN, FRCP ${ }^{5}$ \\ Robert SHERWIN, MD ${ }^{6}$ \\ BERNARD ZinMAN, MD ${ }^{7}$
}

beneficial effect on diabetes-specific microvascular complications, including retinopathy, nephropathy, and neuropathy, in the setting of type 1 diabetes $(4,5)$; in type 2 diabetes, more intensive treatment strategies have likewise been demonstrated to reduce microvascular complications (6-8). Intensive glycemic management resulting in lower AlC levels has also been shown to have a beneficial effect on cardiovascular disease (CVD) complications in type 1 diabetes $(9,10)$; however, current studies have failed to demonstrate a beneficial effect of intensive diabetes therapy on CVD in type 2 diabetes (11-13).

The development of new classes of

From the ${ }^{1}$ Diabetes Center, Massachusetts General Hospital, Boston, Massachusetts; the ${ }^{2}$ University of North Carolina School of Medicine, Chapel Hill, North Carolina; the ${ }^{3}$ Clinical Center for Research Excellence, Charles R. Drew University, Los Angeles, California; the ${ }^{4}$ Department of Internal Medicine, University of Pisa, Pisa, Italy; the ${ }^{5}$ Diabetes Trials Unit, Oxford Centre for Diabetes, Endocrinology and Metabolism, Oxford University, Oxford, U.K.; the ${ }^{6}$ Department of Internal Medicine and Yale Center for Clinical Investigation, Yale University School of Medicine, New Haven, Connecticut; and the ${ }^{7}$ Samuel Lunenfeld Research Institute, Mount Sinai Hospital, University of Toronto, Toronto, Ontario, Canada.

Corresponding author: David. M. Nathan, dnathan@partners.org.

This article is being simultaneously published in 2009 by Diabetes Care and Diabetologia by the American Diabetes Association and the European Association for the Study of Diabetes.

An American Diabetes Association consensus statement represents the authors' collective analysis, evaluation, and opinion at the time of publication and does not represent official association opinion.

DOI: $10.2337 / \mathrm{dc} 08-9025$

(c) 2009 by the American Diabetes Association and Springer. Copying with attribution allowed for any non-commercial use of the work.

blood glucose-lowering medications to supplement the older therapies, such as lifestyle-directed interventions, insulin, sulfonylureas, and metformin, has increased the number of treatment options available for type 2 diabetes. Whether used alone or in combination with other blood glucose-lowering interventions, the increased number of choices available to practitioners and patients has heightened uncertainty regarding the most appropriate means of treating this widespread disease (14). Although numerous reviews on the management of type 2 diabetes have been published in recent years (1517), practitioners are often left without a clear pathway of therapy to follow. We developed the following consensus approach to the management of hyperglycemia in the nonpregnant adult to help guide health care providers in choosing the most appropriate interventions for their patients with type 2 diabetes.

\section{Process}

The guidelines and algorithm that follow are derived from two sources. One source is the clinical trials that address the effectiveness and safety of the different modalities of therapy. Here, the writing group reviewed a wide variety of studies related to the use of drugs as monotherapy or in combination to lower glycemia. Unfortunately, the paucity of high-quality evidence in the form of well-controlled clinical trials that directly compare different diabetes treatment regimens remains a major impediment to recommending one class of drugs, or a particular combination of therapies, over another.

The second source of material that informed our recommendations was clinical judgement, that is, our collective knowledge and clinical experience, which takes into account benefits, risks, and costs in the treatment of diabetes. As in all clinical decision making, an evidence-based review of 
the literature must also be supplemented by value judgements, where the benefits of treatment are weighed against risks and costs in a subjective fashion. While we realize that others may have different judgements, we believe that the recommendations made in this new iteration of our treatment algorithm will guide therapy and result in improved glycemic control and health status over time.

\section{Glycemic goals of therapy}

Controlled clinical trials, such as the Diabetes Control and Complications Trial (DCCT) (4) and the Stockholm Diabetes Study in type 1 diabetes (5) and the UK Prospective Diabetes Study (UKPDS) $(6,7)$ and Kumamoto study (8) in type 2 diabetes, have helped to establish the glycemic goals of therapy that result in improved long-term outcomes. The clinical trials, in concert with epidemiological data $(18,19)$, support decreasing glycemia as an effective means of reducing long-term microvascular and neuropathic complications. The most appropriate target levels for blood glucose, on a day-today basis, and A1C, as an index of chronic glycemia, have not been systematically studied. However, both the DCCT (4) and the UKPDS $(6,7)$ had as their goals the achievement of glycemic levels in the nondiabetic range. Neither study was able to maintain AlC levels in the nondiabetic range in their intensive treatment groups, achieving mean levels over time of $\sim 7 \%$, which is 4 SDs above the nondiabetic mean.

The most recent glycemic goal recommended by the American Diabetes Association, selected on the basis of practicality and the projected reduction in complications over time, is, in general, an $\mathrm{AlC}$ level of $<7 \%$ (1). The most recent glycemic goal set by the International Diabetes Federation is an AlC level of $<6.5 \%$. The upper limit of the nondiabetic range is $6.1 \%$ (mean $\pm \mathrm{SD}$. AlC level of $5 \pm 2 \%$ ) with the DCCT/UKPDSstandardized assay, which has been promulgated through the National Glycohemoglobin Standardization Program (NGSP) and adopted by the vast majority of commercially available assays (20). Several recent clinical trials have aimed for $\mathrm{A} 1 \mathrm{C}$ levels $\leq 6.5 \%$ with a variety of interventions $(11,12)$. The results of the Action to Control Cardiovascular Risk in Diabetes (ACCORD) study, which had the primary objective of decreasing CVD with interventions aimed at achieving an AlC level of $<6.0 \%$ vs. interventions aimed at achieving an AlC level of $<7.9 \%$, showed excess CVD mortality in the intensive treatment group (11). Results from the Action in Diabetes and Vascular Disease: Preterax and Diamicron MR Controlled Evaluation (ADVANCE) trial and the Veterans Affairs Diabetes Trial, both of which had different interventions and study populations than ACCORD, did not demonstrate any excess total or CVD mortality with intensive regimens that achieved AlC levels comparable with the $6.5 \%$ in ACCORD $(12,13)$. However, none of the studies has demonstrated a benefit of intensive glycemic control on their primary CVD outcomes. Our consensus is that an AlC level of $\geq 7 \%$ should serve as a call to action to initiate or change therapy with the goal of achieving an AlC level of $<7 \%$. We are mindful that this goal is not appropriate or practical for some patients, and clinical judgement based on the potential benefits and risks of a more intensified regimen needs to be applied for every patient. Factors such as life expectancy, risk of hypoglycemia, and the presence of CVD need to be considered for every patient before intensifying the therapeutic regimen.

Assiduous attention to abnormalities other than hyperglycemia that accompany type 2 diabetes, such as hypertension and dyslipidaemia, has been shown to improve microvascular and cardiovascular complications. Readers are referred to published guidelines for a discussion of the rationale and goals of therapy for the nonglycemic risk factors, as well as recommendations on how to achieve them $(1,21,22)$.

\section{Principles in selecting antihyperglycemic interventions}

Our choice of specific antihyperglycemic agents is predicated on their effectiveness in lowering glucose, extraglycemic effects that may reduce long-term complications, safety profiles, tolerability, ease of use, and expense.

\section{Effectiveness in lowering glycaemia}

Except for their differential effects on glycemia, there are insufficient data at this time to support a recommendation of one class of glucose-lowering agents, or one combination of medications, over others with regard to effects on complications. In other words, the salutary effects of therapy on long-term complications appear to be predicated predominantly on the level of glycemic control achieved rather than on any other specific attributes of the in- tervention(s) used to achieve glycemic goals. The UKPDS compared three classes of glucose-lowering medications (sulfonylurea, metformin, or insulin) but was unable to demonstrate clear superiority of any one drug over the others with regard to diabetes complications $(6,7)$. However, the different classes do have variable effectiveness in decreasing glycemic levels (Table 1), and the overarching principle in selecting a particular intervention will be its ability to achieve and maintain glycemic goals. In addition to their intention-to-treat analyses demonstrating the superiority of intensive versus conventional interventions, the DCCT and UKPDS demonstrated a strong correlation between mean AlC levels over time and the development and progression of retinopathy and nephropathy $(23,24)$. Therefore, we think it is reasonable to judge and compare blood glucoselowering medications, as well as combinations of such agents, primarily on the basis of their capacity to decrease and maintain A1C levels and according to their safety, specific side effects, tolerability, ease of use, and expense.

\section{Nonglycemic effects of medications}

In addition to variable effects on glycemia, specific effects of individual therapies on CVD risk factors, such as hypertension or dyslipidemia, were also considered important. We also included the effects of interventions that may benefit or worsen the prospects for long-term glycemic control in our recommendations. Examples of these would be changes in body mass, insulin resistance, or insulin secretory capacity in type 2 diabetic patients.

\section{Choosing specific diabetes interventions and their roles in treating type 2 diabetes}

Numerous reviews have focused on the characteristics of the specific diabetes interventions listed below (25-34). In addition, meta-analyses and reviews have summarized and compared the glucoselowering effectiveness and other characteristics of the medications (35-37). The aim here is to provide enough information to justify the choices of medications, the order in which they are recommended, and the use of combinations of therapies. Unfortunately, there is a dearth of high-quality studies that provide headto-head comparisons of the ability of the medications to achieve the currently recommended glycemic levels. The authors 


\begin{tabular}{|c|c|c|c|}
\hline Intervention & $\begin{array}{l}\text { Expected decrease } \\
\text { in AlC with } \\
\text { monotherapy (\%) }\end{array}$ & Advantages & Disadvantages \\
\hline \multicolumn{4}{|l|}{ Tier 1: well-validated core } \\
\hline \multicolumn{4}{|l|}{ Step 1: initial therapy } \\
\hline $\begin{array}{c}\text { Lifestyle to decrease w } \\
\text { increase activity }\end{array}$ & $1.0-2.0$ & Broad benefits & $\begin{array}{l}\text { Insufficient for most within } \\
\text { first year }\end{array}$ \\
\hline Metformin & $1.0-2.0$ & Weight neutral & $\begin{array}{l}\text { GI side effects, contraindicated } \\
\text { with renal insufficiency }\end{array}$ \\
\hline \multicolumn{4}{|l|}{ Step 2: additional therapy } \\
\hline Insulin & $1.5-3.5$ & $\begin{array}{l}\text { No dose limit, rapidly effective, } \\
\text { improved lipid profile }\end{array}$ & $\begin{array}{l}\text { One to four injections daily, } \\
\text { monitoring, weight gain, } \\
\text { hypoglycemia, analogues } \\
\text { are expensive }\end{array}$ \\
\hline Sulfonylurea & $1.0-2.0$ & Rapidly effective & $\begin{array}{l}\text { Weight gain, hypoglycemia } \\
\text { (especially with } \\
\text { glibenclamide or } \\
\text { chlorpropamide) }\end{array}$ \\
\hline \multicolumn{4}{|l|}{ Tier 2: less well validated } \\
\hline TZDs & $0.5-1.4$ & $\begin{array}{l}\text { Improved lipid profile } \\
\text { (pioglitazone), potential } \\
\text { decrease in MI (pioglitazone) }\end{array}$ & $\begin{array}{l}\text { Fluid retention, CHF, weight } \\
\text { gain, bone fractures, } \\
\text { expensive, potential increase } \\
\text { in MI (rosiglitazone) }\end{array}$ \\
\hline GLP-1 agonist & $0.5-1.0$ & Weight loss & $\begin{array}{l}\text { Two injections daily, frequent } \\
\text { GI side effects, long-term } \\
\text { safety not established, } \\
\text { expensive }\end{array}$ \\
\hline \multicolumn{4}{|l|}{ Other therapy } \\
\hline$\alpha$-Glucosidase inhibitor & $0.5-0.8$ & Weight neutral & $\begin{array}{l}\text { Frequent GI side effects, three } \\
\text { times/day dosing, expensive }\end{array}$ \\
\hline Glinide & $0.5-1.5^{\mathrm{a}}$ & Rapidly effective & $\begin{array}{l}\text { Weight gain, three times/day } \\
\text { dosing, hypoglycemia, } \\
\text { expensive }\end{array}$ \\
\hline Pramlintide & $0.5-1.0$ & Weight loss & $\begin{array}{l}\text { Three injections daily, } \\
\text { frequent GI side effects, } \\
\text { long-term safety not } \\
\text { established, expensive }\end{array}$ \\
\hline DPP-4 inhibitor & $0.5-0.8$ & Weight neutral & $\begin{array}{l}\text { Long-term safety not } \\
\text { established, expensive }\end{array}$ \\
\hline
\end{tabular}

${ }^{a}$ Repaglinide more effective in lowering AlC than nateglinide. CHF, congestive heart failure; GI, gastrointestinal; MI, myocardial infarction.

highly recommend that such studies be conducted. However, even in the absence of rigorous, comprehensive studies that directly compare the efficacy of all available glucose-lowering treatments and their combinations, we feel that there are enough data regarding the characteristics of the individual interventions to provide the guidelines below.

An important intervention that is likely to improve the probability that a patient will have better long-term control of diabetes is to make the diagnosis early, when the metabolic abnormalities of diabetes are usually less severe. Lower levels of glycemia at the time of initial therapy are associated with lower AlC levels over time and decreased long-term complications (38).

\section{Lifestyle interventions}

The major environmental factors that increase the risk of type 2 diabetes are overnutrition and a sedentary lifestyle, with consequent overweight and obesity $(39,40)$. Not surprisingly, interventions that reverse or improve these factors have been demonstrated to have a beneficial effect on control of glycemia in established type 2 diabetes (41). Unfortunately, the high rate of weight regain has limited the role of lifestyle interventions as an effective means of controlling glycemia in the long term. The most convincing long-term data indicating that weight loss effectively lowers glycemia have been generated in the follow-up of type 2 diabetic patients who have had bariatric surgery. In this setting, with a mean sustained weight loss of $>20 \mathrm{~kg}$, diabetes is virtually eliminated (42-45). In addition to the beneficial effects of weight loss on glycemia, weight loss and exercise improve coincident CVD risk factors, such as blood pressure and atherogenic lipid profiles, and ameliorate other consequences of obesity $(41,46,47)$. There are few adverse consequences of such life- 
style interventions other than difficulty in incorporating them into usual lifestyle and sustaining them and the usually minor musculoskeletal injuries and potential problems associated with neuropathy, such as foot trauma and ulcers, that may occur as a result of increased activity. Theoretically, effective weight loss, with its pleiotropic benefits, safety profile, and low cost, should be the most cost-effective means of controlling diabetes-if it could be achieved and maintained over the long term.

Given these beneficial effects, which are usually seen rapidly-within weeks to months_-and often before there has been substantial weight loss (47), a lifestyle intervention program to promote weight loss and increase activity levels should, with rare exceptions, be included as part of diabetes management. Weight loss of as little as $4 \mathrm{~kg}$ will often ameliorate hyperglycemia. However, the limited long-term success of lifestyle programs to maintain glycemic goals in patients with type 2 diabetes suggests that the large majority of patients will require the addition of medications over the course of their diabetes.

\section{Medications}

The characteristics of currently available glucose-lowering interventions, when used as monotherapy, are summarized in Table 1. The glucose-lowering effectiveness of individual therapies and combinations demonstrated in clinical trials is predicated not only on the intrinsic characteristics of the intervention but also on the duration of diabetes, baseline glycemia, previous therapy, and other factors. A major factor in selecting a class of drugs, or a specific medication within a class, to initiate therapy or when changing therapy, is the ambient level of glycemic control. When levels of glycemia are high (e.g., AlC >8.5\%), classes with greater and more rapid glucose-lowering effectiveness, or potentially earlier initiation of combination therapy, are recommended; however, patients with recent-onset diabetes often respond adequately to less intensive interventions than those with longer-term disease (48). When glycemic levels are closer to the target levels (e.g., AlC $<7.5 \%$ ), medications with lesser potential to lower glycemia and/or a slower onset of action may be considered.

Obviously, the choice of glycemic goals and the medications used to achieve them must be individualized for each patient, balancing the potential for lowering AlC and anticipated long-term benefit with specific safety issues, as well as other characteristics of regimens, including side effects, tolerability, ease of use, long-term adherence, expense, and the nonglycemic effects of the medications. Type 2 diabetes is a progressive disease characterized by worsening glycemia; higher doses and additional medications are required over time if treatment goals are to be met.

Metformin. In most of the world, metformin is the only biguanide available. Its major effect is to decrease hepatic glucose output and lower fasting glycemia. Typically, metformin monotherapy will lower AlC levels by $\sim 1.5$ percentage points $(27,49)$. It is generally well tolerated, with the most common adverse effects being gastrointestinal. Metformin monotherapy is not usually accompanied by hypoglycemia and has been used safely, without causing hypoglycemia, in patients with prediabetic hyperglycemia (50). Metformin interferes with vitamin $\mathrm{B}_{12}$ absorption but is very rarely associated with anemia (27). The major nonglycemic effect of metformin is either weight stability or modest weight loss, in contrast with many of the other blood glucoselowering medications. The UKPDS demonstrated a beneficial effect of metformin therapy on CVD outcomes (7), which needs to be confirmed. Renal dysfunction is considered a contraindication to metformin use because it may increase the risk of lactic acidosis, an extremely rare (less than 1 case per 100,000 treated patients) but potentially fatal complication (51). However, recent studies have suggested that metformin is safe unless the estimated glomerular filtration rate falls to $<30 \mathrm{ml} / \mathrm{min}$ (52).

Sulfonylureas. Sulfonylureas lower glycemia by enhancing insulin secretion. In terms of efficacy, they appear to be similar to metformin, lowering AlC levels by $\sim 1.5$ percentage points $(26,49)$. The major adverse side effect is hypoglycemia, which can be prolonged and life threatening, but such episodes, characterized by a need for assistance, coma, or seizure, are infrequent. However, severe episodes are relatively more frequent in the elderly. Chlorpropamide and glibenclamide (known as glyburide in the U.S. and Canada), are associated with a substantially greater risk of hypoglycemia than other second-generation sulfonylureas (gliclazide, glimepiride, glipizide, and their extended formulations), which are preferable (Table 1) $(53,54)$. In addition, weight gain of $\sim 2 \mathrm{~kg}$ is common following the initiation of sulfonylurea therapy.
Although the onset of the glucoselowering effect of sulfonylurea monotherapy is relatively rapid compared with, for example, the thiazolidinediones (TZDs), maintenance of glycemic targets over time is not as good as monotherapy with a TZD or metformin (55). Sulfonylurea therapy was implicated as a potential cause of increased CVD mortality in the University Group Diabetes Program (UGDP) study (56). Concerns raised by the UGDP that sulfonylureas, as a drug class, may increase CVD mortality in type 2 diabetes were not substantiated by the UKPDS or ADVANCE study $(6,12)$. The glycemic benefits of sulfonylureas are nearly fully realized at half-maximal doses, and higher doses should generally be avoided.

Glinides. Like the sulfonylureas, the glinides stimulate insulin secretion, although they bind to a different site within the sulfonylurea receptor (28). They have a shorter circulating half-life than the sulfonylureas and must be administered more frequently. Of the two glinides currently available in the U.S., repaglinide is almost as effective as metformin or the sulfonylureas, decreasing AlC levels by $\sim 1.5$ percentage points. Nateglinide is somewhat less effective in lowering AlC than repaglinide when used as monotherapy or in combination therapy $(57,58)$. The risk of weight gain is similar to that for the sulfonylureas, but hypoglycemia may be less frequent, at least with nateglinide, than with some sulfonylureas $(58,59)$

$\boldsymbol{\alpha}$-Glucosidase inhibitors. $\alpha$-Glucosidase inhibitors reduce the rate of digestion of polysaccharides in the proximal small intestine, primarily lowering postprandial glucose levels without causing hypoglycemia. They are less effective in lowering glycemia than metformin or the sulfonylureas, reducing AlC levels by 0.5-0.8 percentage points (29). Since carbohydrate is absorbed more distally, malabsorption and weight loss do not occur; however, increased delivery of carbohydrate to the colon commonly results in increased gas production and gastrointestinal symptoms. In clinical trials, 25-45\% of participants have discontinued $\alpha$-glucosidase inhibitor use as a result of this side effect $(29,60)$.

One clinical trial examining acarbose as a means of preventing the development of diabetes in high-risk individuals with impaired glucose tolerance showed an unexpected reduction in severe CVD outcomes 
(60). This potential benefit of $\alpha$-glucosidase inhibitors needs to be confirmed.

Thiazolidinediones. Thiazolidinediones (TZDs or glitazones) are peroxisome proliferator-activated receptor $\gamma$ modulators; they increase the sensitivity of muscle, fat, and liver to endogenous and exogenous insulin ("insulin sensitizers") (31). The data regarding the blood glucose-lowering effectiveness of TZDs when used as monotherapy have demonstrated a $0.5-1.4$ percentage point decrease in AlC. The TZDs appear to have a more durable effect on glycemic control, particularly compared with sulfonylureas (55). The most common adverse effects with TZDs are weight gain and fluid retention, with peripheral edema and a twofold increased risk for congestive heart failure $(61,62)$. There is an increase in adiposity, largely subcutaneous, with some reduction in visceral fat shown in some studies. The TZDs either have a beneficial (pioglitazone) or neutral (rosiglitazone) effect on atherogenic lipid profiles $(63,64)$. Several meta-analyses have suggested a $30-40 \%$ relative increase in risk for myocardial infarction $(65,66)$ with rosiglitazone. On the other hand, the Prospective Pioglitazone Clinical Trial in macrovascular events (PROactive) demonstrated no significant effects of pioglitazone compared with placebo on the primary CVD outcome (a composite of all-cause mortality, nonfatal and silent myocardial infarction, stroke, major leg amputation, acute coronary syndrome, coronary artery bypass graft or percutaneous coronary intervention, and leg revascularization) after 3 years of follow-up (67). Pioglitazone was associated with a $16 \%$ reduction in death, myocardial infarction, and stroke- a controversial secondary end point reported to have marginal statistical significance (67). Meta-analyses have supported a possible beneficial effect of pioglitazone on CVD risk (68). Although the data are less than conclusive for a CVD risk with rosiglitazone or a CVD benefit with pioglitazone, we have previously advised (69) caution in using either TZD on the basis that they are both associated with increased risks of fluid retention and congestive heart failure and an increased incidence of fractures in women and perhaps in men $(55,61,62,70)$. Although the metaanalyses discussed above are not conclusive regarding the potential cardiovascular risk associated with rosiglitazone, given that other options are now recom- mended, the consensus group members unanimously advised against using rosiglitazone. Currently, in the U.S., the TZDs are approved for use in combination with metformin, sulfonylureas, glinides, and insulin.

Insulin. Insulin is the oldest of the currently available medications and, therefore, the treatment with which we have the most clinical experience. It is also the most effective at lowering glycemia. Insulin can, when used in adequate doses, decrease any level of elevated AlC to, or close to, the therapeutic goal. Unlike the other blood glucose-lowering medications, there is no maximum dose of insulin beyond which a therapeutic effect will not occur. Relatively large doses of insulin $(\geq 1$ unit/kg), compared with those required to treat type 1 diabetes, may be necessary to overcome the insulin resistance of type 2 diabetes and lower AlC to the target level. Although initial therapy is aimed at increasing basal insulin supply, usually with intermediate- or long-actinginsulins, patients may also require prandial therapy with short- or rapid-acting insulins (Fig. 1). The very rapid-acting and long-acting insulin analogues have not been shown to lower AlC levels more effectively than the older, rapid-acting or intermediate-acting formulations (7173). Insulin therapy has beneficial effects on triacylglycerol and HDL cholesterol levels, especially in patients with poor glycemic control (74), but is associated with weight gain of $\sim 2-4 \mathrm{~kg}$, which is probably proportional to the correction of glycemia and predominantly the result of the reduction of glycosuria. Insulin therapy is also associated with hypoglycemia, albeit much less frequently than in type 1 diabetes. In clinical trials aimed at normoglycemia and achieving a mean AlC of $\sim 7 \%$, severe hypoglycemic episodes (defined as requiring help from another person to treat) occurred at a rate of between one and three per 100 patient-years (8,75-77), compared with 61 per 100 patient-years in the DCCT intensive therapy group (4). Insulin analogues with longer, nonpeaking profiles decrease the risk of hypoglycemia modestly compared with $\mathrm{NPH}$, and analogues with very short durations of action reduce the risk of hypoglycemia compared with regular insulin (76,77).

Glucagon-like peptide-1 agonists (exenatide). Glucagon-like peptide-1 (GLP-1) 7-37, a naturally occurring peptide produced by the L-cells of the small intestine, potentiates glucose-stimulated insulin secretion. Exendin-4 has homology with the human GLP-1 sequence but has a longer circulating half-life. It binds avidly to the GLP-1 receptor on the pancreatic $\beta$-cell and augments glucosemediated insulin secretion (32). Synthetic exendin-4 (exenatide) was approved for use in the U.S. in 2005 and is administered twice per day by subcutaneous injection. Although there are less published data on this new compound than the other blood glucose-lowering medications, exendin-4 appears to lower AlC levels by $0.5-1$ percentage points, mainly by lowering postprandial blood glucose levels (78-81). Exenatide also suppresses glucagon secretion and slows gastric motility. It is not associated with hypoglycemia but causes a relatively high frequency of gastrointestinal disturbances, with $30-$ $45 \%$ of treated patients experiencing one or more episodes of nausea, vomiting, or diarrhea (78-81). These side effects tend to abate over time. In published trials, exenatide is associated with weight loss of 2-3 kg over 6 months, some of which may be a result of its gastrointestinal side effects. Recent reports have suggested a risk for pancreatitis associated with use of GLP agonists; however, the number of cases is very small and whether the relationship is causal or coincidental is not clear at this time. Currently, exenatide is approved for use in the U.S. with sulfonylurea, metformin, and/or a TZD. Several other GLP-1 agonists and formulations are under development.

Amylin agonists (pramlintide). Pramlintide is a synthetic analogue of the $\beta$-cell hormone amylin. It is administered subcutaneously before meals and slows gastric emptying, inhibits glucagon production in a glucose-dependent fashion, and predominantly decreases postprandial glucose excursions (33). In clinical studies, AlC has been decreased by $0.5-0.7$ percentage points (82). The major clinical side effects of this drug are gastrointestinal in nature. $\sim 30 \%$ of treated participants in the clinical trials have developed nausea, but this side effect tends to abate with time on therapy. Weight loss associated with this medication is $\sim 1-1.5 \mathrm{~kg}$ over 6 months; as with exenatide, some of the weight loss may be the result of gastrointestinal side effects. Currently, pramlintide is approved for use in the U.S. only as adjunctive therapy with regular insulin or rapid-acting insulin analogues. 
Start with bedtime intermediate-acting insulin or bedtime or morning long-acting insulin (can initiate with 10 units or 0.2 units per $\mathrm{kg}$ )

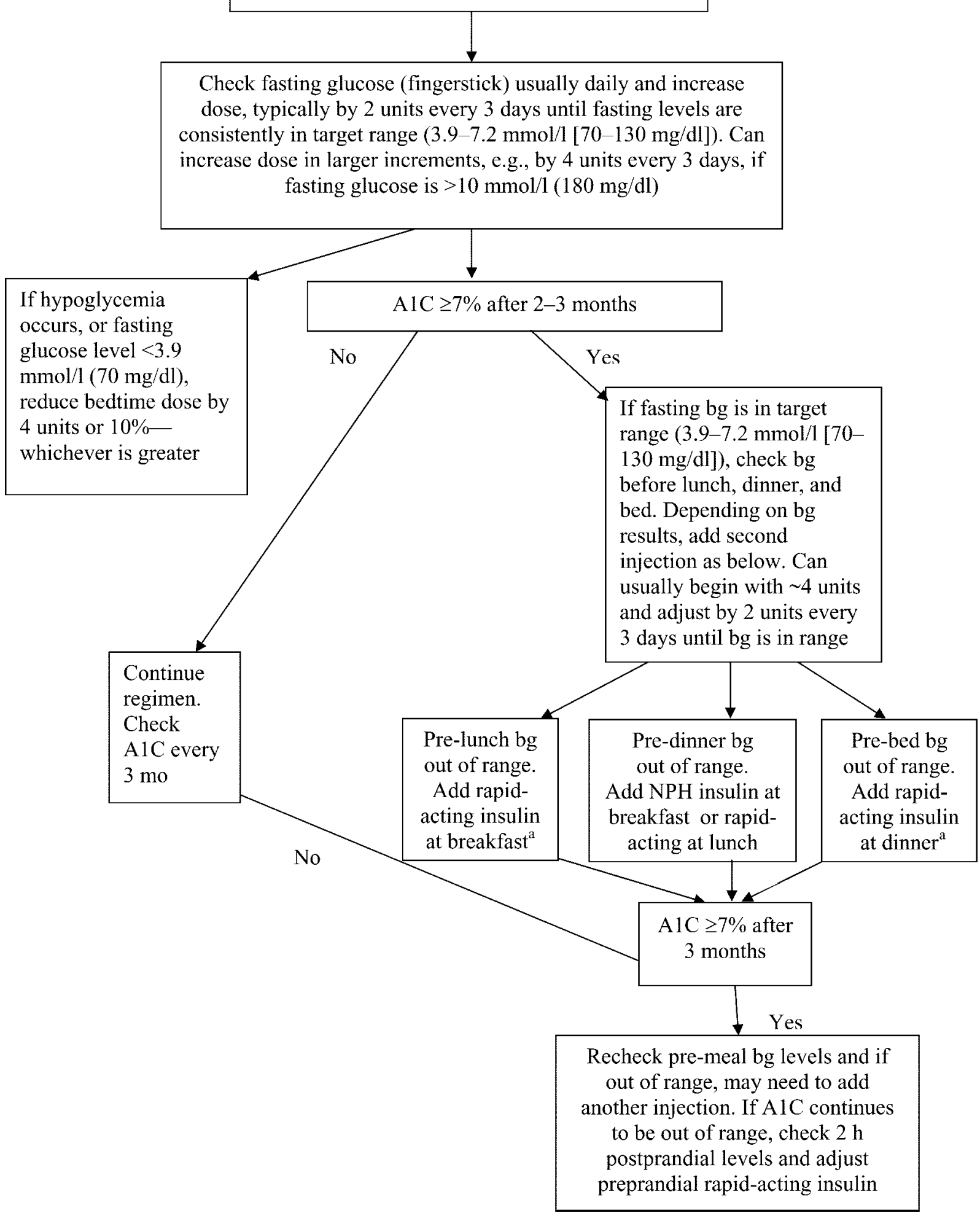

Figure 1-Initiation and adjustment of insulin regimens. Insulin regimens should be designed taking lifestyle and meal schedule into account. The algorithm can only provide basic guidelines for initiation and adjustment of insulin. See reference 90 for more detailed instructions. ${ }^{a}$ Premixed insulins not recommended during adjustment of doses; however, they can be used conveniently, usually before breakfast and/or dinner, if proportion of rapid-and intermediate-acting insulins is similar to the fixed proportions available. bg, blood glucose. 


\section{TITRATION OF METFORMIN}

1. Begin with low-dose metformin $(500 \mathrm{mg}$ ) taken once or twice per day with meals (breakfast and/or dinner) or $850 \mathrm{mg}$ once per day.

2. After 5-7 days, if gastrointestinal side effects have not occurred, advance dose to 850 , or two $500 \mathrm{mg}$ tablets, twice per day (medication to be taken before breakfast and/or dinner).

3. If gastrointestinal side effects appear as doses advanced, decrease to previous lower dose and try to advance the dose at a later time.

4. The maximum effective dose can be up to $1,000 \mathrm{mg}$ twice per day but is often $850 \mathrm{mg}$ twice per day. Modestly greater effectiveness has been observed with doses up to about 2,500 mg/day. Gastrointestinal side effects may limit the dose that can be used.

5. Based on cost considerations, generic metformin is the first choice of therapy. A longer-acting formulation is available in some countries and can be given once per day.

Dipeptidyl peptidase four inhibitors. GLP-1 and glucose-dependent insulinotropic peptide (GIP), the main insulinotropic peptides of intestinal origin (incretins), are rapidly degraded by dipeptidyl peptidase four (DPP-4). DPP-4 is a member of a family of cell membrane proteins that are expressed in many tissues, including immune cells (34). DPP-4 inhibitors are small molecules that enhance the effects of GLP-1 and GIP, increasing glucose-mediated insulin secretion and suppressing glucagon secretion $(83,84)$. The first oral DPP-4 inhibitor, sitagliptin, was approved by the Food and Drug Administration in October 2006 for use as monotherapy or in combination with metformin or TZDs. Another DPP-4 inhibitor, vildagliptin, was approved in Europe in February 2008, and several other compounds are under development. In clinical trials performed to date, DPP-4 inhibitors lower AlClevels by $0.6-0.9$ percentage points and are weight neutral and relatively well tolerated $(83,84)$. They do not cause hypoglycemia when used as monotherapy. A fixed-dose combination pill with metformin is available. The potential for this class of compounds to interfere with immune function is of concern; an increase in upper respiratory infections has been reported (34).

\section{How to initiate diabetes therapy and advance interventions}

Except in rare circumstances, such as diabetic ketoacidosis or patients who are extremely catabolic or hyperosmolar or who are unable to hydrate themselves adequately (see SPECIAL CONSIDERATIONS/PATIENTS below), hospitalization is not required for initiation or adjustment of therapy. The pa- tient is the key player in the diabetes care team and should be trained and empowered to adjust medications with the guidance of health care professionals to achieve glycemic goals and to prevent and treat hypoglycemia. Many patients may be managed effectively with monotherapy; however, the progressive nature of the disease will require the use of combination therapy in many, if not most, patients over time, to achieve and maintain glycemia in the target range.

The measures of glycemia that are initially targeted on a day-to-day basis are fasting and preprandial glucose levels. Self-monitoring of blood glucose (SMBG) is an important element in adjusting or adding new interventions and, in particular, in titrating insulin doses. The need for and number of required SMBG measurements are not clear (85) and are dependent on the medications used. Oral glucose-lowering regimens that do not include sulfonylureas or glinides, and are therefore not likely to cause hypoglycemia, usually do not require SMBG (86). However, SMBG may be used to determine whether therapeutic blood glucose targets are being achieved and for adjustment of treatment regimens without requiring the patient to have laboratory-based blood glucose testing. Insulin therapy requires more frequent monitoring.

The levels of plasma or capillary glucose (most meters that measure fingerstick capillary samples are adjusted to provide values equivalent to plasma glucose) that should result in long-term glycemia in the nondiabetic target range, as measured by $\mathrm{AlC}$, are fasting and preprandial levels between 3.9 and 7.2 $\mathrm{mmol} / \mathrm{l}$ (70 and $130 \mathrm{mg} / \mathrm{dl})$. If AlC levels remain above the desired target despite preprandial levels that are in range, postprandial levels, usually measured 90-120 min after a meal, may be checked. They should be $<10 \mathrm{mmol} / \mathrm{l}(180 \mathrm{mg} / \mathrm{dl})$ to achieve AlC levels in the target range.

Attempts to achieve target glycemic levels with regimens including sulfonylureas or insulin may be associated with modest hypoglycemia, with glucose levels in the $3.1-3.9 \mathrm{mmol} / \mathrm{l}(55-70 \mathrm{mg} / \mathrm{dl})$ range. These episodes are generally well tolerated, easily treated with oral carbohydrate such as glucose tablets or 120 $180 \mathrm{ml}$ (4-6 oz) of juice or nondiet soda, and rarely progress to more severe hypoglycemia, including loss of consciousness or seizures.

\section{Algorithm}

The algorithm (Fig. 2) takes into account the characteristics of the individual interventions, their synergies, and expense. The goal is to achieve and maintain AlC levels of $<7 \%$ and to change interventions at as rapid a pace as titration of medications allows when target glycemic goals are not being achieved. Mounting evidence suggests that aggressive lowering of glycemia, especially with insulin therapy, in newly diagnosed diabetes can result in sustained remissions, i.e., normoglycemia without need for glucose-lowering medications $(87,88)$. Type 2 diabetes is a progressive disease (89), and patients should be informed that they are likely to require the addition of glucose-lowering medications over time.

The amylin agonists, $\alpha$-glucosidase inhibitors, glinides, and DPP-4 inhibitors are not included in the two tiers of preferred agents in this algorithm, owing to their lower or equivalent overall glucoselowering effectiveness compared with the first- and second-tier agents and/or to their limited clinical data or relative expense (Table 1). However, they may be appropriate choices in selected patients.

Tier 1: well-validated core therapies These interventions represent the best established and most effective and costeffective therapeutic strategy for achieving the target glycemic goals. The tier one algorithm is the preferred route of therapy for most patients with type 2 diabetes.

Step 1: lifestyle intervention and metformin. Based on the numerous demonstrated short- and long-term benefits that accrue when weight loss and increased levels of activity are achieved and maintained, as well as the cost-effectiveness of lifestyle interventions when they succeed, 
Tier 1: Well-validated core therapies

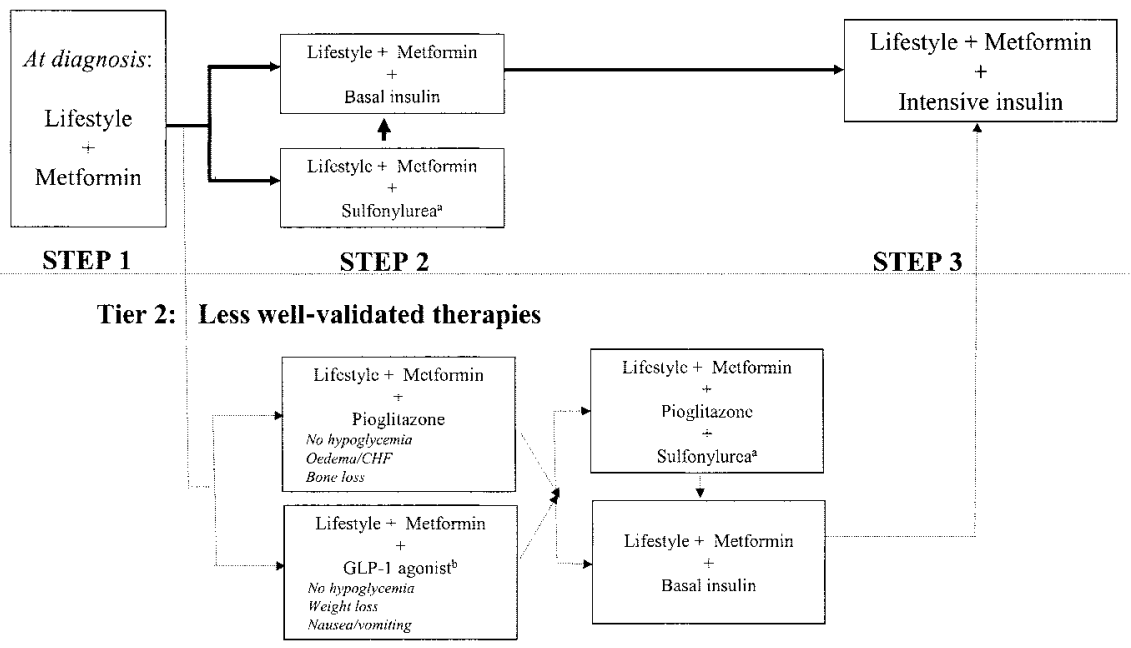

Figure 2-Algorithm for the metabolic management of type 2 diabetes; Reinforce lifestyle interventions at every visit and check A1C every 3 months until A1C is $<7 \%$ and then at least every 6 months. The interventions should be changed if $A 1 C$ is $\geq 7 \%$. ${ }^{a}$ Sulfonylureas other than glybenclamide (glyburide) or chlorpropamide. ${ }^{b}$ Insufficient clinical use to be confident regarding safety. See text box, entitled titRation OF METFORMIN. See Fig. 1 for initiation and adjustment of insulin. CHF, congestive heart failure.

the consensus is that lifestyle interventions should be initiated as the first step in treating new-onset type 2 diabetes (Fig. 2). These interventions should be implemented by health care professionals with appropriate training — usually registered dietitians experienced in behavioral modification-and be sensitive to ethnic and cultural differences among populations. Moreover, lifestyle interventions to improve glucose, blood pressure, and lipid levels, and to promote weight loss or at least avoid weight gain, should remain an underlying theme throughout the management of type 2 diabetes, even after medications are used. For the $10-20 \%$ of patients with type 2 diabetes who are not obese or overweight, modification of dietary composition and activity levels may play a supporting role, but medications are still generally required early in the course of diabetes (see SPECIAL CONSIDERATIONS/PATIENTS below).

The authors recognize that for most individuals with type 2 diabetes, lifestyle interventions fail to achieve or maintain the metabolic goals either because of failure to lose weight, weight regain, progressive disease, or a combination of factors. Therefore, our consensus is that metformin therapy should be initiated concurrently with lifestyle intervention at diagnosis. Metformin is recommended as the initial pharmacological therapy, in the absence of specific contraindications, for its effect on glycemia, absence of weight gain or hypoglycemia, generally low level of side effects, high level of acceptance, and relatively low cost. Metformin treatment should be titrated to its maximally effective dose over 1-2 months, as tolerated (see text box, entitled Titration of Metformin). Rapid addition of other glucose-lowering medications should be considered in the setting of persistent symptomatic hyperglycemia.

Step 2: addition of a second medication. If lifestyle intervention and the maximal tolerated dose of metformin fail to achieve or sustain the glycemic goals, another medication should be added within 2-3 months of the initiation of therapy or at any time when the target AlC level is not achieved. Another medication may also be necessary if metformin is contraindicated or not tolerated. The consensus regarding the second medication added to metformin was to choose either insulin or a sulfonylurea (Fig. 2). As discussed above, the AlC level will determine in part which agent is selected next, with consideration given to the more effective glycemia-lowering agent, insulin, for patients with an AlC level of $>8.5 \%$ or with symptoms secondary to ehyperglycemia. Insulin can be initiated with a basal (intermediate- or long-acting) insulin (see Fig. 1 for suggested initial insulin regimens) (90). However, many newly diagnosed type 2 diabetic patients will usu- ally respond to oral medications, even if symptoms of ehyperglycemia are present (48).

Step 3: further adjustments. If lifestyle, metformin, and sulfonylurea or basal insulin do not result in achievement of target glycemia, the next step should be to start, or intensify, insulin therapy (Fig. 1). Intensification of insulin therapy usually consists of additional injections that might include a short- or rapid-acting insulin given before selected meals to reduce postprandial glucose excursions (Fig. 1). When insulin injections are started, insulin secretagogues (sulfonylurea or glinides) should be discontinued, or tapered and then discontinued, since they are not considered to be synergistic. Although addition of a third oral agent can be considered, especially if the AlC level is close to target (A1C $<8.0 \%$ ), this approach is usually not preferred, as it is no more effective in lowering glycemia, and is more costly, than initiating or intensifying insulin (91).

\section{Tier 2: less well-validated therapies}

In selected clinical settings, this secondtier algorithm may be considered. Specifically, when hypoglycemia is particularly undesirable (e.g., in patients who have hazardous jobs), the addition of exenatide or pioglitazone may be considered. Rosiglitazone is not recommended. If promotion of weight loss is a major consideration and the AlC level is close to target $(<8.0 \%)$, exenatide is an option. If these interventions are not effective in achieving target AlC, or are not tolerated, addition of a sulfonylurea could be considered. Alternatively, the tier two interventions should be stopped and basal insulin started.

\section{Rationale for selecting specific combinations}

More than one medication will be necessary for the majority of patients over time. Selection of the individual agents should be made on the basis of their glucoselowering effectiveness and other characteristics listed in Table 1. However, when adding second antihyperglycemic medications, the synergy of particular combinations and other interactions should be considered. In general, antihyperglycemic drugs with different mechanisms of action will have the greatest synergy. Insulin plus metformin (92) is a particularly effective means of lowering glycemia while limiting weight gain. 


\section{Special considerations/patients}

In the setting of severely uncontrolled diabetes with catabolism, defined as fasting plasma glucose levels $>13.9 \mathrm{mmol} / \mathrm{l}$ ( 250 $\mathrm{mg} / \mathrm{dl}$ ), random glucose levels consistently above $16.7 \mathrm{mmol} / \mathrm{l}(300 \mathrm{mg} / \mathrm{dl}$ ), AlC above $10 \%$, or the presence of ketonuria, or as symptomatic diabetes with polyuria, polydipsia and weight loss, insulin therapy in combination with lifestyle intervention is the treatment of choice. Some patients with these characteristics will have unrecognized type 1 diabetes; others will have type 2 diabetes with severe insulin deficiency. Insulin can be titrated rapidly and is associated with the greatest likelihood of returning glucose levels rapidly to target levels. After symptoms are relieved and glucose levels decreased, oral agents can often be added and it may be possible to withdraw insulin, if preferred.

\section{Conclusions}

Type 2 diabetes is epidemic. Its long-term consequences translate into enormous human suffering and economic costs; however, much of the morbidity associated with long-term microvascular and neuropathic complications can be substantially reduced by interventions that achieve glucose levels close to the nondiabetic range. Although new classes of medications and numerous combinations have been demonstrated to lower glycemia, current-day management has failed to achieve and maintain the glycemic levels most likely to provide optimal healthcare status for people with diabetes.

\section{Summary}

The guidelines and treatment algorithm presented here emphasize the following:

- Achievement and maintenance of near normoglycaemia (AlC <7.0\%)

- Initial therapy with lifestyle intervention and metformin

- Rapid addition of medications, and transition to new regimens, when target glycemic goals are not achieved or sustained

- Early addition of insulin therapy in patients who do not meet target goals

\section{Duality of interest}

D.M.N. has received a research grant for investigator-initiated research from sanofi aventis and support for educational programs from GlaxoSmithKline. J.B.B. has conducted research and/or served on advisory boards under contract between the
University of North Carolina and Amylin, Becton Dickinson, Bristol-Myers Squibb, Hoffman-LaRoche, Eli Lilly, GlaxoSmithKline, Novo Nordisk, Merck, Novartis, Pfizer, and sanofi aventis. M.B.D. has received research support from Eli Lilly, Merck, and Pfizer; has served on advisory boards for Amylin, GlaxoSmithKline, Merck, and sanofi aventis; and has been on speakers bureaus for Amylin, Eli Lilly, GlaxoSmithKline, and Pfizer. E.F. has received research support from Astra Zeneca, Merck Sharpe \& Dohme, and Novartis and serves on scientific advisory boards for Amylin, AstraZeneca, GlaxoSmithKline, Roche, Merck Sharpe \& Dohme, Novartis, Servier, sanofi aventis, Boehringer Ingelheim, and Takeda. R.R.H. has received research support from Bristol-Myers Squibb, GlaxoSmithKline, Merck Sante, Novo Nordisk, Pfizer, and Pronova and has served on advisory boards and/or received honoraria for speaking engagements from Amylin, GlaxoSmithKline, Lilly, Merck Sharp \& Dohme, Novartis, and sanofi aventis. R.S. has served on advisory boards for Amylin, Astra Zeneca, Boehringer Ingelheim, DiObex, Eli Lilly, Insulet, Merck, MannKind, and Novartis. B.Z. has received research support from GlaxoSmithKline, Merck, Novartis, and Novo Nordisk and has been a member of scientific advisory boards and/or received honoraria for speaking engagements from Amylin, Eli Lilly, GlaxoSmithKline, Merck, Novartis, Pfizer, sanofi aventis, and Servier.

\section{References}

1. American Diabetes Association: Standards of medical care in diabetes-2008 (Position Statement). Diabetes Care 31(Suppl. 1): S12-S54, 2008

2. European Diabetes Policy Group: A desktop guide to type 2 diabetes mellitus. Diabet Med 16:716-730, 1999

3. National Institute for Clinical Excellence: Clinical guidelines for type 2 diabetes mellitus: management of blood glucose [article online], 2002. Available from http://www.nice.org.uk./Guidancet/CG66

4. Diabetes Control and Complications Trial Research Group: The effect of intensive diabetes treatment on the development and progression of long-term complications in insulin-dependent diabetes mellitus: the Diabetes Control and Complications Trial. N Engl J Med 329:978-986, 1993

5. Reichard P, Nilsson B-Y, Rosenqvist U: The effect of long-term intensified insulin treatment on the development of microvascular complications of diabetes mellitus. N Engl J Med 329:304-309, 1993
6. UK Prospective Diabetes Study (UKPDS) Group: Intensive blood glucose control with sulphonylureas or insulin compared with conventional treatment and risk of complication in patients with type 2 diabetes (UKPDS 33). Lancet 352:837-853, 1998

7. UK Prospective Diabetes Study (UKPDS) Group: Effect of intensive blood glucose control with metformin on complication in overweight patients with type 2 diabetes (UKPDS 34). Lancet 352:854-865, 1998

8. Ohkubo Y, Kishikawa H, Araki E, et al.: Intensive insulin therapy prevents the progression of diabetic microvascular complications in Japanese patients with NIDDM: a randomized prospective 6-year study. Diabetes Res Clin Pract 28:103-117, 1995

9. Diabetes Control and Complications Trial/ Epidemiology of Diabetes Interventions and Complications Research Group: Intensive diabetes therapy and carotid intima-media thickness in type 1 diabetes. N Engl J Med 348:2294-2303, 2003

10. Diabetes Control and Complications Trial/ Epidemiology of Diabetes Interventions and Complications Research Group: Intensive diabetes treatment and cardiovascular disease in patients with type 1 diabetes. N Engl J Med 353:2643-2653, 2005

11. The Action to Control Cardiovascular Risk in Diabetes Study Group: Effects of intensive glucose lowering in type 2 diabetes. N Engl J Med 358:2545-2559, 2008

12. The ADVANCE Collaborative Group: Intensive blood glucose control and vascular outcomes in patients with type 2 diabetes. N Engl J Med 358:2560-2572, 2008

13. Abraira C, Duckworth WC, Moritz T: Glycaemic separation and risk factor control in the Veterans Affairs Diabetes Trial: an interim report. Diabetes Obes Metab. 29 July 2008 [Epub ahead of print]

14. Nathan DM: Finding new treatments for diabetes-how many, how fast ... how good? N Engl J Med 356:437-440, 2007

15. Nathan DM: Initial management of glycemia in type 2 diabetes mellitus. N Engl J Med 347:1342-1349, 2002

16. Sheehan MT: Current therapeutic options in type 2 diabetes mellitus: a practical approach. Clin Med Res 1:189-200, 2003

17. Inzucchi SE: Oral antihyperglycemic therapy for type 2 diabetes. JAMA 287: 360-372, 2002

18. Klein R, Klein BEK, Moss SE, et al.: Glycosylated hemoglobin predicts the incidence and progression of diabetic retinopathy. JAMA 260:2864-2871, 1988

19. Chase HP, Jackson WE, Hoops SL, et al.: Glucose control and the renal and retinal complications of insulin-dependent diabetes. JAMA 261:1155-1160, 1989

20. Little RR, Rohlfing CL, Wiedmeyer H-M, et al.: The National Glycohemoglobin 
Standardization Program (NGSP): a five year progress report. Clin Chem 47:19851992, 2001

21. Grundy SM, Cleeman JI, Merz NB, et al.: Implications of recent clinical trials for the National Cholesterol Education Program Adult Treatment Panel III guidelines. Circulation 110:227-239, 2004

22. Chobanian AV, Bakris GL, Black HR, et al.: The seventh report of the Joint $\mathrm{Na}$ tional Committee on Prevention, Detection, Evaluation and Treatment of High Blood Pressure: the JNC 7 report. JAMA 289:2560-2572, 2003

23. DCCT Research Group: The association between glycemic exposure and longterm diabetic complications in the Diabetes Control and Complications Trial. Diabetes 44:968-983, 1995

24. Stratton IM, Adler AI, Neil HA, et al.: Association of glycaemia with macrovascular and microvascular complications of type 2 diabetes (UKPDS 35): prospective observational study. BMJ 321:405-412, 2000

25. National Institutes of Health: Clinical Guidelines on the Identification, Evaluation, and Treatment of Overweight and Obesity in Adults: the Evidence Report. Bethesda, MD, National Heart, Lung, and Blood Institute, National Institutes of Health, 1999

26. Groop L: Sulfonylureas in NIDDM. Diabetes Care 15:737-747, 1992

27. Bailey CJ, Turner RC: Metformin. N Engl J Med 334:574-583, 1996

28. Malaisse WJ: Pharmacology of the meglitinide analogs: new treatment options for type 2 diabetes mellitus. Treat Endocrinol 2:401-414, 2003

29. Van de Laar FA, Lucassen PL, Akkermans $\mathrm{RP}$, et al.: Alpha-glucosidase inhibitors for type 2 diabetes mellitus. Cochrane Database Syst Rev 2:CD003639, 2005

30. Genuth S: Insulin use in NIDDM. Diabetes Care 13:1240-1264, 1990

31. Yki-Jarvinen H: Drug therapy: thiazolidinediones. N Engl J Med 351:1106, 2004

32. Drucker DJ: Biologic actions and therapeutic potential of the proglucagonderived peptides. Nature Endocrinol Metab 1:22-31, 2005

33. Schmitz O, Brock B, Rungby J: Amylin agonists: a novel approach in the treatment of diabetes. Diabetes 53 (Suppl. 3): S233-S238, 2004

34. Richter B, Bandeira-Echtler E, Bergerhoff $\mathrm{K}$, et al.: Dipeptidyl peptidase-4 (DPP-4) inhibitors for type 2 diabetes mellitus. Cochrane Database Syst Rev 2:CD006739, 2008

35. Amori RE, Lau J, Pittas AG: Efficacy and safety of incretin therapy in type 2 diabetes: a systematic review and meta-analysis. JAMA 298:194-206, 2007

36. Monami M, Lamannac C, Marchionni N, et al.: Comparison of different drugs as add-on treatments to metformin in type 2 diabetes: a meta-analysis. Diabetes Res Clin Pract 79:196-203, 2008

37. Bolen S, Feldman L, Vassy J, et al.: Systematic review: comparative effectiveness and safety of oral medications for type 2 diabetes mellitus. Ann Intern Med 147: 386-399, 2007

38. Colagiuri S, Cull CA, Holman RR, et al.: Are lower fasting plasma glucose levels at diagnosis of type 2 diabetes associated with improved outcomes? U.K. Prospective Diabetes Study 61. Diabetes Care 25: 1410-1417, 2002

39. Harris MI: Epidemiologic correlates of NIDDM in Hispanics, whites and blacks in the U.S. population. Diabetes Care 14 (Suppl. 3):639-648, 1991

40. Rewers M, Hamman RF: Risk factors for non-insulin dependent diabetes. In Diabetes in America. 2nd ed. Harris M, Ed. Bethesda, MD, National Institutes of Health, 1995, p. 179-220 (NIH publ. no. 95-1468)

41. Look AHEAD Research Group: Reduction in weight and cardiovascular disease risk factors in individuals with type 2 diabetes: one-year results of the Look AHEAD trial. Diabetes Care 30:137483, 2007

42. Pories WJ, Swanson MS, MacDonald KG, et al:: Who would have thought it? An operation proves to be the most effective therapy for adult-onset diabetes mellitus. Ann Surg 222:339-350, 1995

43. Sjostrom L, Lindroos AK, Peltonen M, et al.: Lifestyle, diabetes, and cardiovascular risk factors 10 years after bariatric surgery. N Engl J Med 351:2683-2693, 2004

44. Dixon JB, O'Brien PE, Playfair J, et al.: Adjustable gastric banding and conventional therapy for type 2 diabetes: a randomized controlled trial. JAMA 299:316323, 2008

45. Pontiroli AE, Folli F, Paganelli M, et al.: Laparoscopic gastric banding prevents type 2 diabetes and arterial hypertension and induces their remission in morbid obesity: a 4-year case-controlled study. Diabetes Care 28:2703-2709, 2005

46. Diabetes Prevention Program Research Group: Impact of intensive lifestyle and metformin therapy on cardiovascular disease risk factors in the Diabetes Prevention Program. Diabetes Care 28:888-894, 2005

47. Hadden DR, Montgomery DAD, Skelly RJ, et al.: Maturity onset diabetes mellitus: response to intensive dietary management. BMJ 3:276-278, 1975

48. Peters AL, Davidson MB: Maximal dose glyburide in markedly symptomatic patients with type 2 diabetes: a new use for an old friend. J Clin Endocrinol Metab 81: 2423, 1996

49. DeFronzo R, Goodman A, the Multicenter Metformin Study Group: Efficacy of metformin in patients with non-insulin-dependent diabetes mellitus. $N$ Engl J Med
333:541-549, 1995

50. Diabetes Prevention Program Research Group: Reduction in incidence of type 2 diabetes with lifestyle intervention or metformin. N Engl J Med 346:393-403, 2002

51. Salpeter S, Greyber E, Pasternak G, et al.: Risk of fatal and nonfatal lactic acidosis with metformin use in type 2 diabetes mellitus. Cochrane Database Syst Rev 1: CD002967, 2006

52. Shaw JS, Wilmot RL, Kilpatrick ES: Establishing pragmatic estimated GFR thresholds to guide metformin prescribing. Diabet Med 24:1160-1163, 2007

53. Holstein A, Plaschke A, Egberts E-H: Lower incidence of severe hypoglycemia in patients with type 2 diabetes treated with glimepiride versus glibenclamide. Diabetes Metab Res Rev 17:467-473, 2001

54. Gangji AS, Cukierman T, Gerstein HC, et al.: A systematic review and meta-analysis of hypoglycemia and cardiovascular events: a comparison of glyburide with other secretagogues and with insulin. Diabetes Care 30:389-394, 2007

55. Kahn SE, Haffner SM, Heise MA, et al.: Glycemic durability of rosiglitazone, metformin, or glyburide monotherapy. N Engl J Med 355:2427-2443, 2006

56. Meinert CL, Knatterud GL, Prout TE, et al.: The University Group Diabetes Program: a study of the effect of hypoglycemic agents on vascular complications in patients with adult-onset diabetes. II. Mortality results. Diabetes 19 (Suppl. 1): 789-830, 1970

57. Rosenstock J, Hassman DR, Madder RD, et al.: Repaglinide versus nateglinide monotherapy: a randomized, multicenter study. Diabetes Care 27:1265-1270, 2004

58. Gerich J, Raskin P, Jean-Louis L, et al.: PRESERVE-beta: two year efficacy and safety of initial combination therapy with nateglinide or glyburide plus metformin. Diabetes Care 28:2093-2099, 2005

59. Damsbo P, Clauson P, Marbury TC, et al.: A double-blind randomized comparison of meal-related glycemic control by repaglinide and glyburide in well-controlled type 2 diabetic patients. Diabetes Care 22: 789-794, 1999

60. Chiasson JL, Josse RG, Gomis R, et al.: Acarbose treatment and the risk of cardiovascular disease and hypertension in patients with impaired glucose tolerance: the STOP-NIDDM Trial. JAMA 290:486494, 2003

61. Home PD, Pocock SJ, Beck-Nielsen H, et al.: Rosiglitazone evaluated for cardiovascular outcomes--an interim analysis. N Engl J Med 357:28-38,

62. Singh S, Loke YK, Furberg CD: Thiazolidinediones and heart failure: a teleoanalysis. Diabetes Care 30:2248-2254, 2007

63. Khan MA, St Peter JV, Xue JL: A prospec- 
tive, randomized comparison of the metabolic effects of pioglitazone or rosiglitazone in patients with type 2 diabetes who were previously treated with troglitazone. Diabetes Care 25:708-711, 2002

64. Goldberg RB, Kendall DM, Deeg MA, et al.: A comparison of lipid and glycemic effects of pioglitazone and rosiglitazone in patients with type 2 diabetes and dyslipidemia. Diabetes Care 28:1547-1554, 2005

65. Nissen SE, Wolski K: Effect of rosiglitazone on the risk of myocardial infarction and death from cardiovascular causes. N Engl J Med 356:2457-2471, 2007

66. Singh S, Loke YK, Furberg CD: Long-term risk of cardiovascular events with rosiglitazone: a meta-analysis. JAMA 298:1189_ 1195, 2007

67. Dormandy JA, Charbonnel B, Eckland DJA, et al.: Secondary prevention of macrovascular events in patients with type 2 diabetes in the PROactive (PROspective pioglitAzone Clinical Trial in macrovascular Events): a randomized controlled trial. Lancet 366:12791289,2005

68. Lincoff AM, Wolski K, Nicholls SJ, et al.: Pioglitazone and risk of cardiovascular events in patients with type 2 diabetes mellitus: a meta-analysis of randomized trials. JAMA 298:1180-1188, 2007

69. Nathan DM, Buse JB, Davidson MB, et al.: Management of hyperglycaemia in type 2 diabetes: a consensus algorithm for the initiation and adjustment of therapy: update regarding the thiazolidinediones. Diabetologia 51:8-11, 2008

70. Meier C, Kraenzlin ME, Bodmer M, et al.: Use of thiazolidinediones and fracture risk. Arch Intern Med 168:820-825, 2008

71. Horvath K, Jeitler K, Berghold A, et al.: Long-acting insulin analogues versus $\mathrm{NPH}$ insulin (human isophane insulin) for type 2 diabetes mellitus. Cochrane Database Syst Rev 2:CD005613, 2007

72. Raskin P, Allen E, Hollander P: Initiating insulin therapy in type 2 diabetes. Diabetes Care 28:260-265, 2005

73. Dailey G, Rosenstock J, Moses RG, et al.:
Insulin glulisine provides improved glycemic control in patients with type 2 diabetes. Diabetes Care 27:2363-2368, 2004

74. Nathan DM, Roussell A, Godine JE: Glyburide or insulin for metabolic control in non-insulin-dependent diabetes mellitus: a randomized double-blind study. Ann Int Med 334-340, 1998

75. Abraira C, Johnson N, Colwell J, et al.: VA Cooperative study on glycemic control and complications in type II diabetes. Diabetes Care 18:1113-1123, 1995

76. Zammitt NN, Frier BM: Hypoglycemia in type 2 diabetes. Diabetes Care 28:29482961, 2005

77. Miller CD, Phillips LS, Ziemer DC, et al.: Hypoglycemia in patients with type 2 diabetes mellitus. Arch Int Med 161:16531659,2005

78. Kendall DM, Riddle MC, Rosenstock J, et al.: Effects of exenatide (exendin-4) on glycemic control and weight over 30 weeks in patients with type 2 diabetes treated with metformin and a sulfonylurea. Diabetes Care 28:1083-1091, 2005

79. DeFronzo RA, Ratner RE, Han J, et al.: Effects of exenatide (exendin-4) on glycemic control and weight over 30 weeks in metformin-treated patients with type 2 diabetes. Diabetes Care 28:1092-1100, 2005

80. Buse JB, Henry RR, Han J, et al.: Effects of exenatide on glycemic control over 30 weeks in sulfonylurea-treated patients with type 2 diabetes. Diabetes Care 27: 2628-2635, 2005

81. Heine RJ, Van Gaal LF, Johns D, et al.: Exenatide versus insulin glargine in patients with suboptimally controlled type 2 diabetes. Ann Int Med 143:559-569, 2005

82. Riddle M, Frias J, Zhang B, et al.: Pramlintide improved glycemic control and reduced weight in patients with type 2 diabetes using basal insulin. Diabetes Care 30:2794-2799, 2007

83. Raz I, Hanefeld M, Xu L, et al.: Efficacy and safety of the dipeptidyl peptidase-4 inhibitor sitagliptin as monotherapy in patients with type 2 diabetes mellitus. Diabetologia 49:2564-2571, 2006

84. Goldstein B, Feinglos M, Lunceford J, et al.: Effect of initial combination therapy with sitagliptin, a dipeptidyl peptidase-4 inhibitor, and metformin on glycemic control in patients with type 2 diabetes. Diabetes Care 30:1979-1987, 2007

85. Welschen LMC, Bloemendal E, Nijpels G, et al.: Self-monitoring of blood glucose in patients with type 2 diabetes who are not using insulin: a systematic review. Diabetes Care 28:1510-1517, 2005

86. Farmer A, Wade A, Goyder E, et al.: Impact of self monitoring of blood glucose in the management of patients with noninsulin treated diabetes: open parallel group randomised trial. BMJ 335:132, 2007

87. Ilkova H, Glaser B, Tunckale A, et al.: Induction of long-term glycemic control in newly diagnosed type 2 diabetic patients by transient intensive insulin treatment. Diabetes Care 20:1353-1356, 1997

88. Weng J, Li Y, Xu W, et al.: Effect of intensive insulin therapy on beta-cell function and glycemic control in patients with newly diagnosed type 2 diabetes: a multicentre randomized parallel-group trial. Lancet 371: 1753-1760, 2008

89. U.K. Prospective Diabetes Study Group: U.K. Prospective Diabetes Study 16: overview of 6 years' therapy of type II diabetes: a progressive disease. Diabetes 44:1249_ 1258, 1995

90. Hirsch IB, Bergenstal RM, Parkin CG, et al: : A real-world approach to insulin therapy in primary care practice. Clinical Diabetes 23:78-86, 2005

91. Schwartz S, Sievers R, Strange P, et al.: Insulin 70/30 mix plus metformin versus triple oral therapy in the treatment of type 2 diabetes after failure of two oral drugs. Diabetes Care 26:2238-2243, 2003

92. Yki-Jarvinen H, Ryysy L, Nikkila K, et al.: Comparison of bedtime insulin regimens in patients with type 2 diabetes mellitus. Ann Int Med 130:389-396, 1999 